\title{
Gestão da água em usina de concreto: análise do emprego de Moringa oleifera no tratamento de água residuária e proposta de reuso após tratamento
}

\author{
Water management in a concrete plant: \\ Moringa oleifera employment analysis \\ without wastewater treatment and \\ reuse proposal after treatment
}

Thaynara de Almeida Corrêa e Silva ${ }^{1}$, Heber Martins de Paula ${ }^{1}$

\footnotetext{
${ }^{1}$ Curso de Engenharia Civil - Universidade Federal de Goiás, Regional Catalão, CEP 75704-020, Catalão, Goiás, Brasil. e-mail: heberdepaula@ufg.br

e-mail: thaynara.acs@gmail.com
}

\section{RESUMO}

O setor da construção civil, um dos maiores consumidores de matérias-primas e recursos hídricos, vem mostrando sinais rumo à uma produção sustentável. Nesse seguimento, a gestão e reuso de águas residuárias nas centrais dosadoras de concreto corroboraria para diminuição dos efeitos negativos da área com o meio ambiente. No entanto, para o reuso de água residuária tornar-se viável é necessário efetuar o seu tratamento, visando a adequação dos parâmetros como, por exemplo, alcalinidade, cloro residual livre, dureza, pH e turbidez com as normas vigentes. Sendo assim, o presente estudo avaliou as possíveis aplicações para água residuária tratada com o uso do extrato aquoso de Moringa oleifera obtido de duas formas, sendo: apenas em água destilada (EAMO) e outra em água destilada com nitrato de cálcio (EAMO/Ca2+) e com o coagulante químico sulfato de alumínio $\left(\mathrm{Al}_{2}\left(\mathrm{SO}_{4}\right)_{3}\right)$. Os tratamentos analisados possibilitaram redução da alcalinidade em $22 \%$ com EAMO/Ca2+ e $16 \%$ com o extrato $\mathrm{Al}_{2}\left(\mathrm{SO}_{4}\right)_{3}$, diminuição da dureza em $11,4 \%$ com EAMO/Ca2+e 4,7\% com extrato $\mathrm{Al}_{2}\left(\mathrm{SO}_{4}\right)_{3}$ e eficiência de remoção da turbidez superior a $85 \%$ para todos os coagulantes estudados na dosagem ótima. $\mathrm{O}$ pH e o cloro residual livre mantiveram-se constante. Dessa maneira, o tratamento considerado como o melhor, efetuado com EAMO/Ca2+, possibilita empregabilidade da água residuária para fins não potáveis e amassamento do concreto.

Palavras-chave: resíduo líquido, aplicações pós tratamento, Moringa oleifera, concreto, coagulante natural.

\begin{abstract}
The civil construction acivities, great consumers of raw material and water resources, ha demonstrated signs to achieve a sustainable production. In this sector, the management and reuse of residual waters in concrete batchers would contribute in the decrease of negative impacts with relation to environment. However, to make the residual water reuse, viable, it is needed to make its threat, aimming the adequacy of such indicators as, alkalinity, residual free chlorine, hardness, ph and turbidity with the current regulations. Therefore, this article avaluated the possible applications for residual water threated with the use of "moringa oleifera" aqueous extract, obtained by two ways, as: only in distilled water (EAMO) and other in water distilled with calcium nitrate $(\mathrm{EAMO} / \mathrm{Ca} 2+)$ and with aluminium sulfate $\left(\mathrm{Al}_{2}\left(\mathrm{SO}_{4}\right)_{3}\right)$ as the chemical coagulant. The analized threats made the decrease of alkalinity to $22 \%$ with $\mathrm{EAMO} / \mathrm{Ca} 2+$ and $16 \%$ with the $\mathrm{Al}_{2}\left(\mathrm{SO}_{4}\right)_{3}$ extract, decrease of hardness to $11,4 \%$ with $\mathrm{EAMO} / \mathrm{Ca} 2+$ and $4,7 \%$ with $\mathrm{Al}_{2}\left(\mathrm{SO}_{4}\right)_{3}$ and an efficient remove of turbidity, higher than $85 \%$ to all the avaluated coagulants. The ph and free residual chlorine, kept theirselves constant. So, the consideraded best threat, extracted from EAMO/Ca2+, makes the reuse of residual water to non potable ways and concrete kneading.
\end{abstract}

Key-words: liquid waste, post treatment applications, Moringa oleifera, concrete, natural coagulant. 


\section{INTRODUÇÃO}

Os impactos ao meio ambiente em decorrência das ações do homem e as interferências dessa relação são objetos de discussões cada vez mais debatidos no cenário global, visto que, na grande maioria, as atividades acarretam modificações do ambiente natural sem adoção de medidas mitigadoras para atenuar os efeitos nocivos ao mesmo [1].

Nesse sentido, as cobranças sociais, políticas, e, principalmente, econômicas sobre os setores empresariais tem propiciado mudança de conduta, corroborando para adesão de produção com menos impactos ao meio ambiente. Logo, o uso de estratégias econômicas, socioambientais e tecnológicas integradas aos processos e produtos facilita a alteração das linhas de produção tornando-as mais harmonicamente ambientais, aumentando o desempenho referente à aplicação das matérias primas, água e energia através da não-geração, redução ou reciclagem dos resíduos gerados.

O setor da construção civil, um dos maiores consumidores de matérias primas naturais, de acordo com Vieira [2], e um dos fomentadores da economia brasileira, já apresentam indícios de medidas menos impactantes ao meio ambiente, como construções sustentáveis, reaproveitamento de resíduos, aplicação de materiais com incorporação de resíduos e subprodutos, dentre outros.

Nessa perspectiva, as centrais dosadoras de concreto, responsáveis, segundo SNIC [3] em 2012, pela absorção de $19,4 \%$ de todo montante de cimento requerido pelo mercado interno e grande consumidor de recurso hídrico tem como uma das alternativas para aglutinar na produção a consciência ambiental e a gestão de águas residuárias. Segundo Zervaki et al. [4] as centrais dosadoras de concreto utilizam grandes quantidades de água para a produção direta do concreto (geralmente um valor típico de razão de água/cimento igual a 0,5), e em atividades secundárias como higienização dos caminhões misturadores, umectação de agregados, pulverização e limpeza do pátio.

Dessa forma, a gestão das águas residuárias contemplaria a minimização dos danos ambientais e, além disso, contribuiria para a redução do consumo de água potável [5]. Para Lobo e Mullings [6] a gestão de águas residuais tem como meta a descarga zero de resíduos a qual pode ser alcançada mediante reutilização do resíduo líquido com ou sem tratamento prévio após constatação da qualidade.

A qualidade da água residuária (resíduo líquido) das centrais dosadoras de concreto foi objeto de estudo de muitos autores, dentre os quais destacam: Sandrolini e Franzoni [7], Su; Miao e Liu [8], Chatveera et al. [9], Ekolu e Dawneerangen [10], Tsimas e Zervaki [11], Paula e Ilha [12] e Paula e Fernandes [13]. Dentre os resultados obtidos cabe destacar a elevada alcalinidade entre 680 a $2239,5 \mathrm{mg} . \mathrm{L}^{-1}$ de $\mathrm{CaCO}_{3}$, alta dureza com valores maiores $1400 \mathrm{mg} . \mathrm{L}^{-1}$ de $\mathrm{CaCO}_{3}, \mathrm{pH}$ básico variando entre 11,9 a 13,5, turbidez oscilando entre 20 a 700 UNT (Unidades Nefelométricas de Turbidez), cloreto variando de 40 a 195 mg. $\mathrm{L}^{-1}$ e cloro residual entre 0,25 a $0,50 \mathrm{mg} \cdot \mathrm{L}^{-1}$.

Nesse seguimento, Sandrolini e Franzoni [7] e Su; Miao e Liu [8] mostram a necessidade de tratamento prévio da água residuária. O primeiro trabalho justifica que a mesma não pode ser descartada em decorrência do elevado $\mathrm{pH}$ e matéria em suspensão, já o segundo destaca os efeitos prejudiciais do descarte em solo ou água. Cosgun e Esin [14] também enfatizam os efeitos negativos do descarte dos resíduos da central dosadora de concreto no meio ambiente considerando o impacto na estrutura natural, nos habitats e na saúde humana. Contudo, Paula e Ilha [12] propõe o uso dessa mesma água residuária, porém com a introdução de algum tratamento, para atividades como pulverização e lavagem dos caminhões betoneiras. Em outro trabalho Paula, Ilha e Andrade [15] mostram ainda a possibilidade do tratamento dessa água residuária mediante uso da Moringa oleifera associada ao sulfato de alumínio, apontando uma remoção de turbidez acima de $95 \%$.

A Moringa oleifera é uma árvore pertencente à família Moringaceae [16], é empregada em usos medicinais e para alimentação e, além disso, vem sendo estudada em aplicações para tratamento de águas superficiais e residuárias. Ela apresente em sua composição uma proteína com potencial coagulante, o que corrobora para um tratamento natural, gerando menos lodo $[16,17,18,19,20,21]$ e resíduos químicos. Também destaca que o uso desse coagulante natural é biodegradável [16, 17, 19, 20, 22, 23, 24]; inócuo à saúde humana [16, 20, 22, 25]; mais econômico quando comparado à tecnologia dos coagulantes químicos [18, 20, 22, 24]; tratamento simples [18]; ambientalmente correto [16, 23]; baixa toxicidade [17, 19] e reduz a fauna bacteriana $[18,19,20,24]$.

Lo Monaco et al. [26] e Molina; Rodríguez e Ariza [21] apontam que a proteína da MO pode ser potencializada se associada ao elemento cálcio, contudo para o tratamento de águas residuárias de concreto ainda não houve essa constatação. 
Portanto, o foco deste estudo é avaliar as possíveis aplicações para água residuária tratada com o uso do extrato aquoso de Moringa oleifera obtido de duas formas, sendo: apenas em água destilada (EAMO) e outra em água destilada com nitrato de cálcio (EAMO/Ca2+), por fim comparar os parâmetros de qualidade com o tratamento convencional com o coagulante químico sulfato de alumínio.

\section{MATERIAIS E MÉTODOS}

Neste estudo foram utilizados como coagulantes a Moringa oleifera, extraída em água destilada (EAMO) e em água destilada com nitrato de cálcio (EAMO/Ca2+), constituindo os coagulantes naturais; e o sulfato de alumínio $\left(\mathrm{Al}_{2}\left(\mathrm{SO}_{4}\right)_{3}\right)$ como coagulante químico.

\subsection{Preparação dos coagulantes}

As sementes de Moringa oleifera foram coletadas na cidade de Catalão - GO. Para a preparação dos extratos as sementes foram descascadas e colocadas na estufa a $60^{\circ} \mathrm{C}$ durante quatro dias ou até que se observasse constância da massa. Tal procedimento foi efetuado com o objetivo de retirar a umidade natural da semente. Posterior à secagem, as sementes foram trituradas em liquidificador obtendo-se o pó de moringa.

Para o preparo do extrato de Moringa oleifera em água destilada (EAMO), foram utilizados 50 g do pó de moringa diluído em 1,0 L de água destilada, já para o extrato de Moringa oleifera em solução de nitrato de cálcio (EAMO/Ca2+), foram empregados $50 \mathrm{~g}$ do pó de moringa, diluído em 1,0 L de solução de $\mathrm{Ca}\left(\mathrm{NO}_{3}\right)_{2}$ 0,125 mols $\mathrm{L}^{-1}$. Em ambos os extratos, as misturas foram submetidas à agitação de $100 \mathrm{rpm}$, no agitador magnético (DiagTech, modelo DT3110H) durante $30 \mathrm{~min}$, em seguida, foram filtradas com auxílio de papel filtro e guardadas em geladeira a $4{ }^{\circ} \mathrm{C}$ durante 24 horas. Após esse tempo, os extratos estavam aptos a serem utilizados no tratamento proposto.

Para o extrato de sulfato de alumínio (extrato $\mathrm{Al}_{2}\left(\mathrm{SO}_{4}\right)_{3}$ ) foram adicionados $50 \mathrm{~g}$ do pó de sulfato de alumínio (P.A., Quimidrol) em 1,0 L de água destilada, a mistura também foi submetida à agitação de $100 \mathrm{rpm}$, durante 30 min e guardada em geladeira a $4^{\circ} \mathrm{C}$ durante 24 horas.

Todos os extratos foram utilizados até 20 dias após seu preparo, transcorridos esse tempo foram preparados novos extratos.

\subsection{Coleta da água residuária}

A água residuária utilizada neste estudo foi proveniente da linha de produção da empresa de concreto, situada no distrito minero-industrial (DIMIC) da cidade de Catalão - Goiás. Na empresa há um tanque decantador, para o qual é destinado a água residuária, dividido em três câmaras (Figura 1). A primeira câmara, designada Ponto 1, é a de entrada do resíduo líquido (pior situação em termos de qualidade da água residuária); segunda, Ponto 2, corresponde à câmara de decantação na qual há deposição do material sólido; e, a terceira, Ponto 3 , corresponde à câmara de saída.

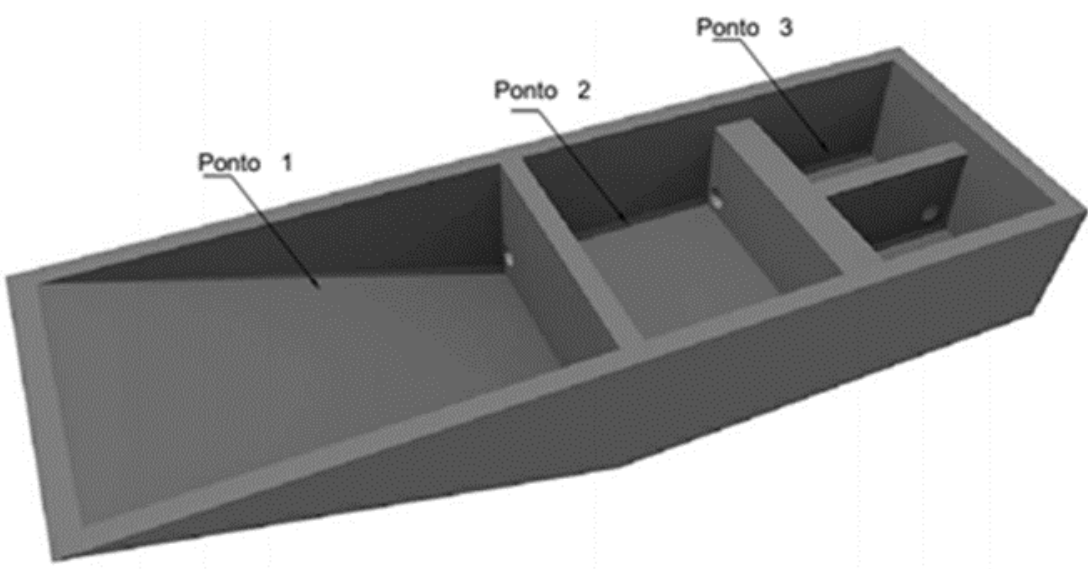

Figura 1: Tanque decantador da empresa BRASMIX

Para o estudo, foi coletada a água residuária do Ponto 1, no período entre janeiro e julho de 2017. O resíduo líquido foi reservado, por até cinco dias após a coleta, na geladeira à temperatura de $4{ }^{\circ} \mathrm{C}$, e agitado antes de cada análise ou ensaio, para uniformizar a amostra. 


\subsection{Definição das concentrações dos coagulantes}

A mensuração da concentração ótima dos extratos foi realizada em duas etapas: na primeira foi efetuada a análise visual de formação de flocos e, mediante resultados observados nesta etapa, realizou-se uma segunda etapa, na qual foram estudadas seis dosagens de coagulante com a finalidade de se obter a dosagem ótima de remoção das variáveis respostas.

$\mathrm{Na}$ primeira etapa foram realizados três ensaios para cada coagulante separadamente, monitorando visualmente o início da formação de flocos. Para tanto, foi adicionado 1,0 L de água residuária em um béquer e colocado em alta rotação no agitador magnético (DiagTech, modelo DT3110H), em média $1200 \mathrm{rpm}$ (20 s${ }^{1}$ ), em seguida, foi adicionado dosagens de coagulante de $0,5 \mathrm{~mL}$ por vez e, transcorridos um minuto da adição, observou-se a formação ou não de flocos em baixa rotação, em média $50 \mathrm{rpm}\left(0,83 \mathrm{~s}^{-1}\right)$. Para o EAMO, a concentração variou de 0 a $20 \mathrm{~mL} \mathrm{~L}^{-1}$ e para os extratos EAMO/Ca+2 e $\mathrm{Al}_{2}\left(\mathrm{SO}_{4}\right)_{3}$, a concentração variou de 0 a $10 \mathrm{~mL} \mathrm{~L}^{-1}$.

A segunda etapa foi efetuada no Jar test (Milan®, modelo JT-203/6) com seis cubas, cada uma contendo 1,0 L de água residuária e as dosagens empregadas foram adotadas com respaldo na análise de formação de flocos (primeira etapa).

O padrão de rotação aplicado no tratamento em estudo é o proposto por Paula [27], que sugere $100 \mathrm{rpm}\left(1,67 \mathrm{~s}^{-1}\right)$ durante 2 min para rotação rápida, seguida de $20 \mathrm{~min}$ a $40 \mathrm{rpm}\left(0,67 \mathrm{~s}^{-1}\right)$. Os coagulantes foram adicionados simultaneamente nos recipientes com água residuária a ser tratada antes do início do teste. Os ensaios foram realizados em triplicatas e os resultados médios foram comparados com uma amostra de referência (resíduo líquido submetido apenas a rotação sem adição de coagulante) de modo a se obter a eficiência do tratamento. A eficiência de tratamento foi medida por meio da remoção da turbidez do efluente, medida após o término dos tempos de sedimentação, que foram 15, 30 e $60 \mathrm{~min}$. A dosagem ótima considerada foi aquela que proporcionou eficiência de remoção de turbidez superior a $99 \%$ com menor dosagem de coagulante.

Cabe salientar que a água residuária tratada contemplava uma elevada turbidez, superior a 100 UNT. Esse fator contribui para maior eficiência da moringa na remoção da turbidez, como dito Paula [27] e Muniz et al. [28] pois, a eficiência de remoção da turbidez utilizando sementes de moringa é maior em águas com maior turbidez inicial.

\subsection{Análise da qualidade da água e possibilidades de reuso}

Mediante a determinação das dosagens ótimas, foram realizados, para melhor mensuração da eficácia do tratamento para cada extrato, testes em triplicatas para cada variável antes e depois do tratamento em três datas diferentes, sendo estas variáveis:

alcalinidade total (Método SM 2320 B - Alfakit@);

cloro residual livre (Método DPD-Alfakit®);

dureza total (Método SM 2340 C - Alfakitß);

pH (Modelo HI - 2221, HANNA®);

turbidez (Modelo DLT - WV, DEL Labß).

Para análise dos resultados, foram consideradas as médias dos valores obtidos das triplicatas e o desvio padrão; e confrontou-se com os valores de referência, mostrados na Tabela 1, obtendo os possíveis reusos do resíduo líquido pós tratamento.

Tabela 1: Parâmetros de comparação para análise da qualidade da água residuária tratada

\begin{tabular}{c|c|c|c|c|c}
\hline $\begin{array}{c}\text { Normas e literatura } \\
\text { referência }\end{array}$ & $\begin{array}{c}\text { Alcalinidade } \\
\left(\mathbf{m g . L ^ { - 1 }} \mathbf{C a C O}\right)\end{array}$ & $\begin{array}{c}\text { Cloro } \\
\text { Residual } \\
\text { Livre } \\
\left(\mathbf{m g . L ^ { - 1 }}\right)\end{array}$ & $\begin{array}{c}\text { Dureza } \\
\left(\mathbf{m g . L ^ { - 1 }} \mathbf{C a C O} \mathbf{C O}_{3}\right)\end{array}$ & pH & $\begin{array}{c}\text { Turbidez } \\
\text { (UNT) }\end{array}$ \\
\hline NBR 15527 [29] & 0,5 a 3,0 & & 6 a 8 & $\begin{array}{c}\text { menos restritos } \\
<5,0\end{array}$ \\
NBR 15900 [30] & & & $\geq 5,0$ &
\end{tabular}




\begin{tabular}{|c|c|c|c|c|c|}
\hline NBR 15575 [31] & & 0,5 a 3,0 & & 6 a 8 & $\begin{array}{c}<2,0 \\
\text { para usos menos } \\
\text { restritivos }<5,0\end{array}$ \\
\hline USEPA [32]* & 50 a 150 & & & 6 a 9 & $\leq 2,0$ \\
\hline VON SPERLING [33] & & & $\begin{array}{c}\text { Classificação da } \\
\text { água } \\
<50 \text { - água mole; } \\
50 \text { a } 150 \text { - água } \\
\text { moderada; } \\
150 \text { a } 300 \text { - água } \\
\text { dura; > } 300 \text { - água } \\
\text { muito dura }\end{array}$ & & \\
\hline
\end{tabular}

*USEPA [32] padrão de qualidade de água indicado para o reuso urbano (para todos os tipos de irrigação, lavagem de veículos, descarga de bacias sanitárias, sistemas de combate a incêndio, sistemas comerciais de ar condicionado, e usos, acessos e exposição similares a estes), sendo (c) valores para água de reuso.

Fonte: Adaptado de Paula e Ilha [12]

\subsection{Análise do tratamento para baixa turbidez}

Determinado o coagulante mais eficiente para o tratamento da água residuária, realizou-se a segunda etapa, para verificar a aplicabilidade do estudo para baixa turbidez, tomando como parâmetro de qualidade a remoção da turbidez.

\section{RESULTADOS}

Mediante a análise visual de formação de flocos pode-se observar como o extrato reagiria com a água residuária no que se refere à dosagem de coagulante para o processo de coagulação.

Na Figura 2 encontram-se os resultados obtidos na etapa de determinação da dosagem ótima de coagulante. É perceptível que EAMO necessita de uma maior dosagem para se obter flocos bem estruturados quando comparado com os extratos EAMO/Ca2+ e $\mathrm{Al}_{2}\left(\mathrm{SO}_{4}\right)_{3}$, além disso, nota-se a similaridade dos resultados do coagulante natural EAMO/Ca2+ com o coagulante químico sulfato de alumínio.

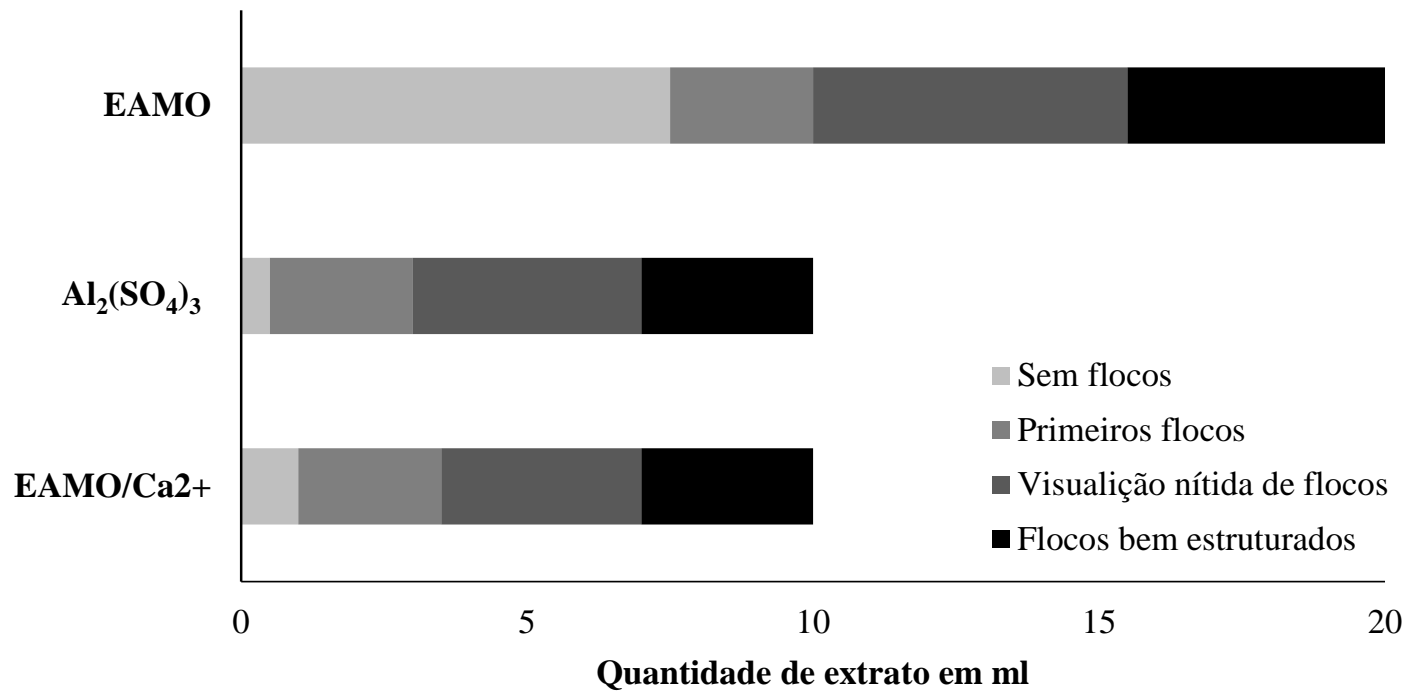

Figura 2: Formação de flocos observada em função da dose de coagulante e do tipo de coagulante empregado.

Quando analisados os resultados dos coagulantes naturais conclui-se que houve maior eficiência na formação de flocos utilizando o EAMO/Ca2+. Segundo Lo Monaco et al. [26] este fato pode ser explicado pela potencialização da ação coagulante da Moringa oleifera devido à presença do cálcio $\left(\mathrm{Ca}^{+2}\right)$ que, 
adsorvidos ao componente ativo do processo de coagulação (proteína), permite a junção entre as moléculas, compondo uma matéria insolúvel o qual é eficaz na aglutinação dos sólidos suspensos mediante interceptação.

Para a determinação das concentrações da segunda etapa foram adotados os valores iniciais de visualização dos primeiros flocos abrangendo dosagens da visualização nítida e as iguais e superiores a formação bem estruturada com intuito de abranger a maior gama de resultados. Para tanto, foram adotadas as dosagens 7, 10, 13, 16, 19 e $21 \mathrm{~mL}$ para o EAMO e 1,5, 3, 6, 9, 12 e $15 \mathrm{~mL}$ para EAMO/Ca2+ e $\mathrm{Al}_{2}\left(\mathrm{SO}_{4}\right)_{3}$, os quais obtiveram comportamento semelhante.

Foram realizados os ensaios para análise de remoção da turbidez; os resultados obtidos são mostrados nas Figuras 3, 4 e 5.

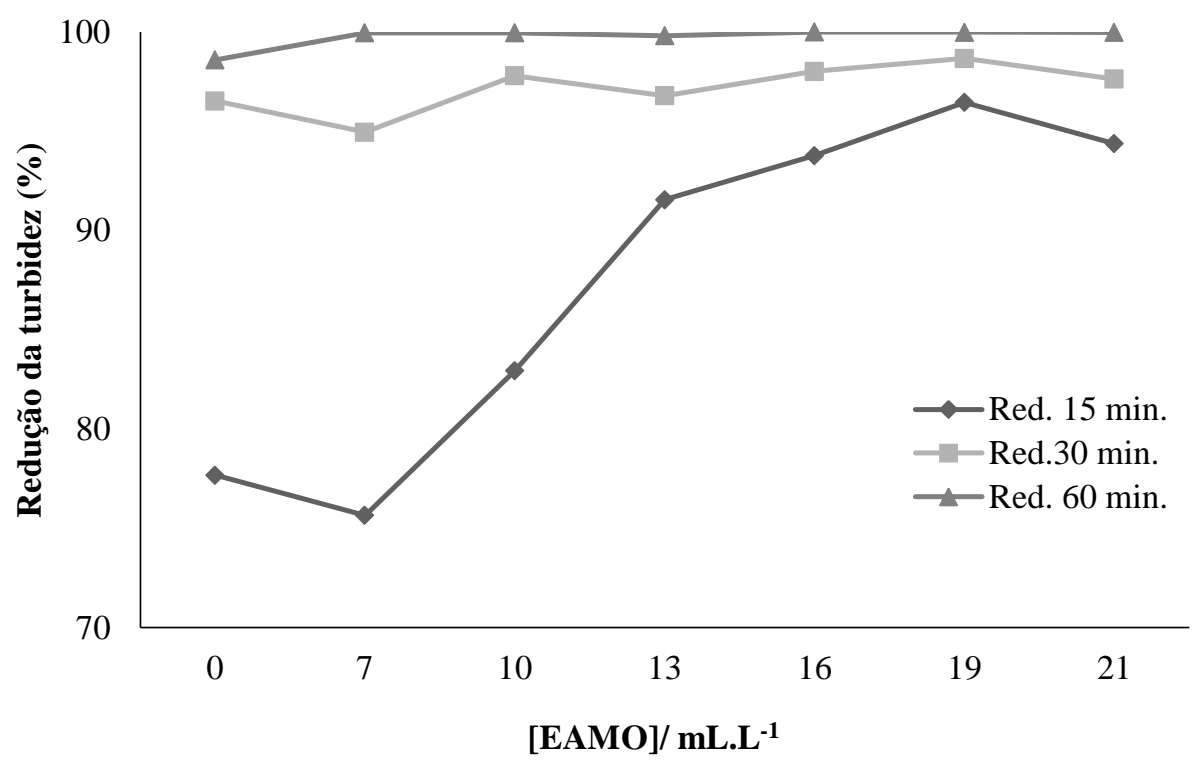

Figura 3: Redução de turbidez da água residuária de usina de concreto utilizando EAMO

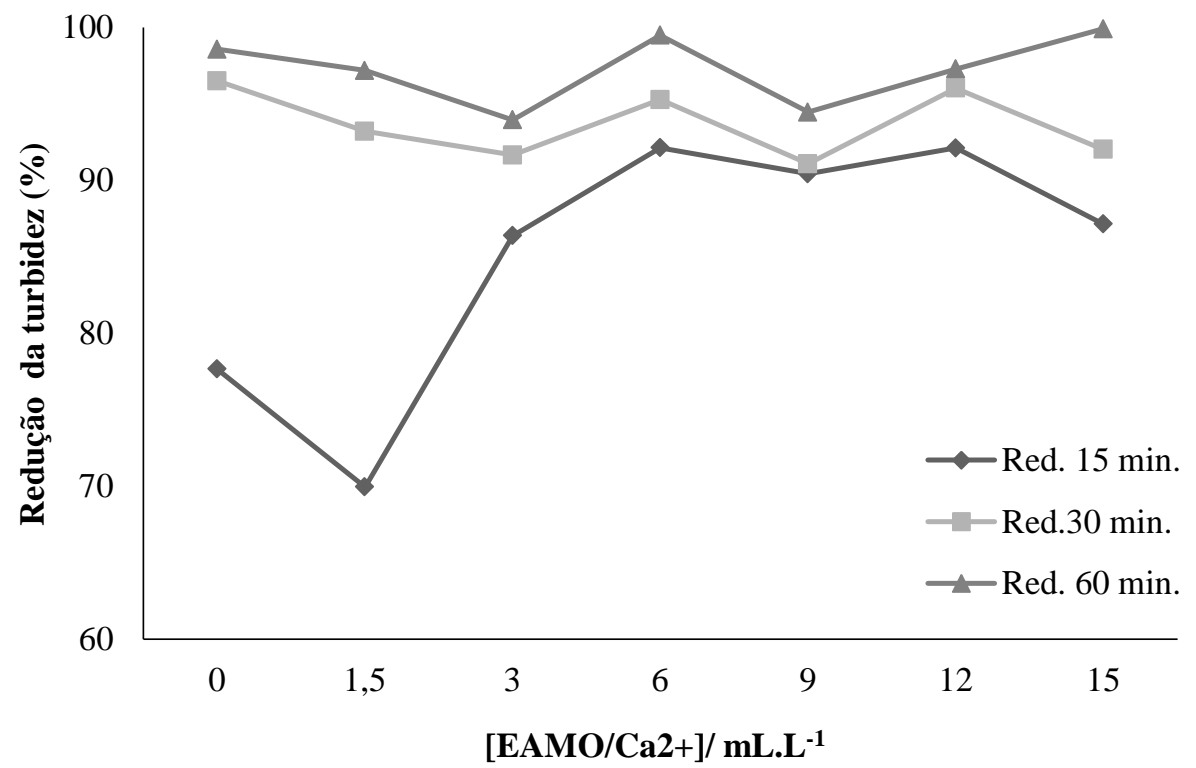

Figura 4: Redução de turbidez da água residuária de usina de concreto utilizando EAMO/Ca2+ 


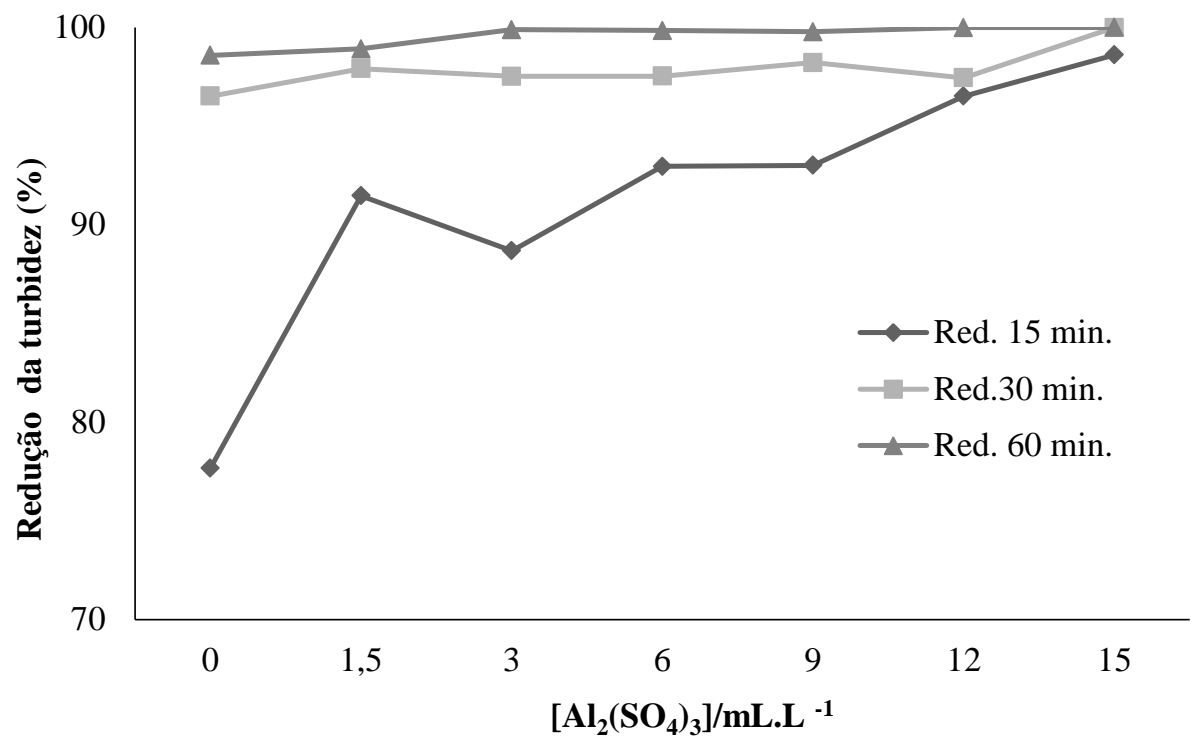

Figura 5: Redução de turbidez da água residuária de usina de concreto utilizando o extrato $\mathrm{Al}_{2}\left(\mathrm{SO}_{4}\right)_{3}$

Analisando a Figura 3, percebe-se que o EAMO proporcionou redução de turbidez acima de $99 \%$ em todas as dosagens, exceto a referência, testadas com 60 minutos de sedimentação, além disso, nota-se uma linearidade na curva de Red. 60 min. (redução de turbidez com 60 minutos) evidenciando que a adição de extrato acima de 7,0 mL não contribui para a remoção dos sólidos suspensos do resíduo líquido. Nesse limiar a dosagem ideal para esse coagulante natural foi de 7,0 mL.L $\mathrm{L}^{-1}$ com o tempo de 60 min de sedimentação.

Para o EAMO/Ca2+, observou-se na Figura 4 uma variação na remoção da turbidez com a adição de extrato, não obtendo uma linearidade em nenhuma das curvas de redução. No entanto, todas as dosagens estudadas apresentaram remoção de turbidez superior a $90 \%$ nos tempos de sedimentação de 30 e 60 min, demonstrando o potencial de uso do coagulante natural associado ao sal no tratamento do resíduo líquido da central dosadora de concreto. Para o processo de coagulação do EAMO/Ca2+ determinou-se que a dosagem ótima foi a de 6,0 mL.L $\mathrm{L}^{-1}$, pois apresentou remoção de turbidez superior a $99 \%$ na curva Red. $60 \mathrm{~min}$.

$\mathrm{O}$ coagulante $\mathrm{Al}_{2}\left(\mathrm{SO}_{4}\right)_{3}$ foi o mais eficiente na remoção da turbidez, apresentando em todas as dosagens e tempo de sedimentação uma remoção de turbidez superior a $90 \%$, mediante análise da Figura 5. Além disso, a curva Red. 60 min. mostrou-se linear após 3,0 mL.L ${ }^{-1}$ de extrato, evidenciando que a partir desse ponto a adição de coagulante não aumenta a eficiência do processo de coagulação; desse modo, a dosagem ótima para o coagulante químico foi de $3,0 \mathrm{~mL} \cdot \mathrm{L}^{-1}$.

Ainda, destaca-se a similaridade das curvas Red.60 min. dos extratos EAMO e $\mathrm{Al}_{2}\left(\mathrm{SO}_{4}\right)_{3}$, Figuras 3 e 5, comprovando a aplicabilidade do coagulante natural no tratamento de água residuária. Todavia salienta-se que para a obtenção da eficiência observada foram empregadas maiores dosagens do extrato EAMO do que do coagulante $\mathrm{Al}_{2}\left(\mathrm{SO}_{4}\right)_{3}$.

Definido a dosagem ótima, foram efetuados os testes para os parâmetros de alcalinidade, cloro residual livre, dureza, $\mathrm{pH}$ e turbidez antes e depois do tratamento em três datas diferentes, cujas respostas obtidas são representadas nas Figuras 6 a 10. 


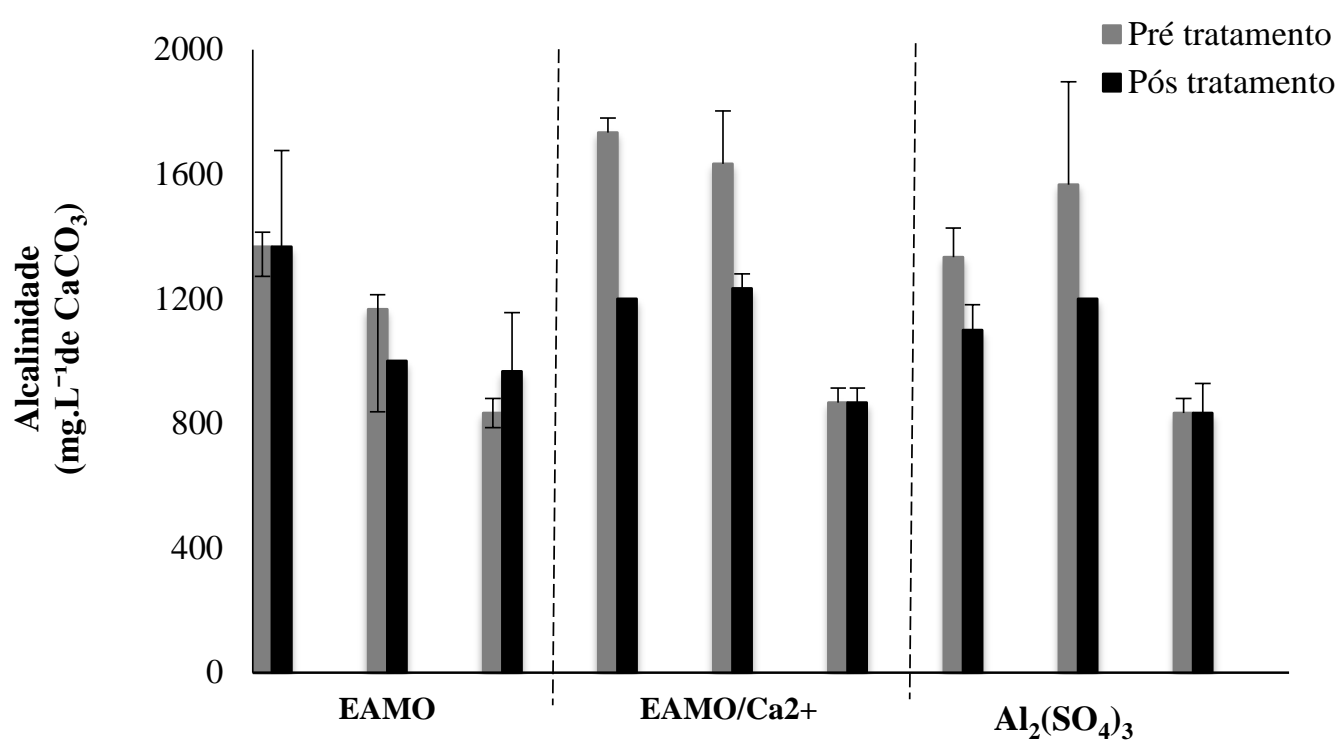

Figura 6: Variação da alcalinidade pré e pós-tratamento em função do coagulante empregado

A alcalinidade variou conforme o coagulante empregado no tratamento, como é observado na Figura 6. Observa-se, ainda, na Figura 6 que o EAMO promoveu modificação na alcalinidade da água, já o EAMO/Ca2+ proporcionou uma diminuição 311,11 mg.L ${ }^{-1} \mathrm{CaCO}_{3}(22 \%)$ enquanto o extrato $\mathrm{Al}_{2}\left(\mathrm{SO}_{4}\right)_{3}$ minorou em $200 \mathrm{mg} . \mathrm{L}^{-1} \mathrm{CaCO}_{3}(16 \%)$. Nesse âmbito o coagulante com melhor eficiência foi o EAMO/Ca2+, todavia, os valores finais de alcalinidade não estão em conformidade com a referência da USEPA [32], que estabelece limites entre 50 e $150 \mathrm{mg} . \mathrm{L}^{-1}$ de $\mathrm{CaCO}_{3}$.

Outro importante parâmetro analisado foi à concentração de cloro. Os valores desse parâmetro indicam o potencial de desinfecção da água tratada, visto que a usina de concreto faz uso de água com adição mínima desse produto. Na Figura 7 são apresentados os resultados do tratamento na concentração de cloro residual livre.

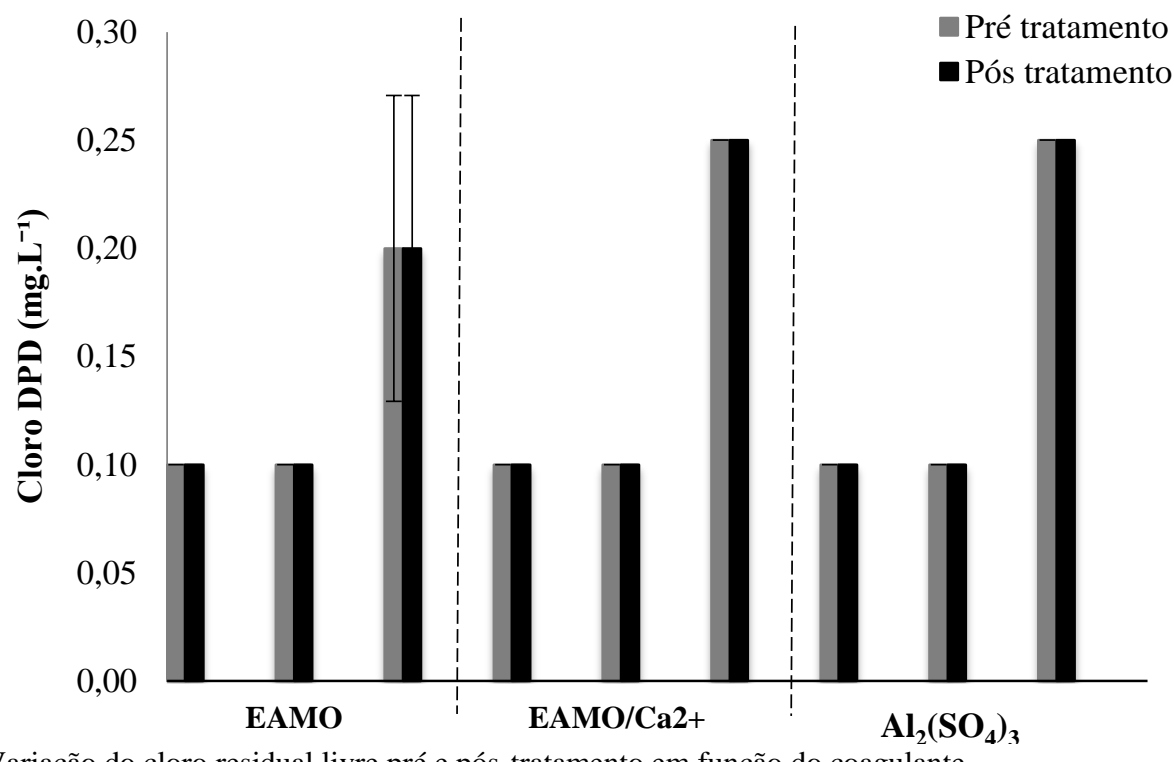

Figura 7: Variação do cloro residual livre pré e pós-tratamento em função do coagulante

Analisando a Figura 7, pode-se observar que os coagulantes naturais e químico utilizados no tratamento da água residuária não modificaram o parâmetro cloro residual livre. Cabe destacar que, os valores obtidos estão em conformidade com as normas NBR 15527[29] e NBR 15575[31] nas quais, o limite varia entre 0,5 a 3,0 mg. $\mathrm{L}^{-1}$, portanto, analisando esta variável o resíduo líquido pode ser utilizado para fins não potáveis. 
Por meio da análise da Figura 8, foi possível observar a variação da dureza da água em função da aplicação dos coagulantes na dosagem considerada ótima. De maneira semelhante à alcalinidade, observa-se aumento de $322,22 \mathrm{mg} . \mathrm{L}^{-1} \mathrm{CaCO}_{3}(38 \%)$ na dureza com utilização do EAMO, e redução de $166,67 \mathrm{mg} . \mathrm{L}^{-1}$ $\mathrm{CaCO}_{3}(11,4 \%)$ com EAMO/Ca2+ e 55,56 mg. $\mathrm{L}^{-1} \mathrm{CaCO}_{3}(4,7 \%)$ com extrato $\mathrm{Al}_{2}\left(\mathrm{SO}_{4}\right)_{3}$. Isto posto, para esta variável, o melhor desempenho é do EAMO/Ca2+, e como base na referência de Von Sperling [33], mesmo após o tratamento, o resíduo líquido é denominado água muito dura para qual o limite é superior à $300 \mathrm{mg} . \mathrm{L}^{-1}$ $\mathrm{CaCO}_{3}$.

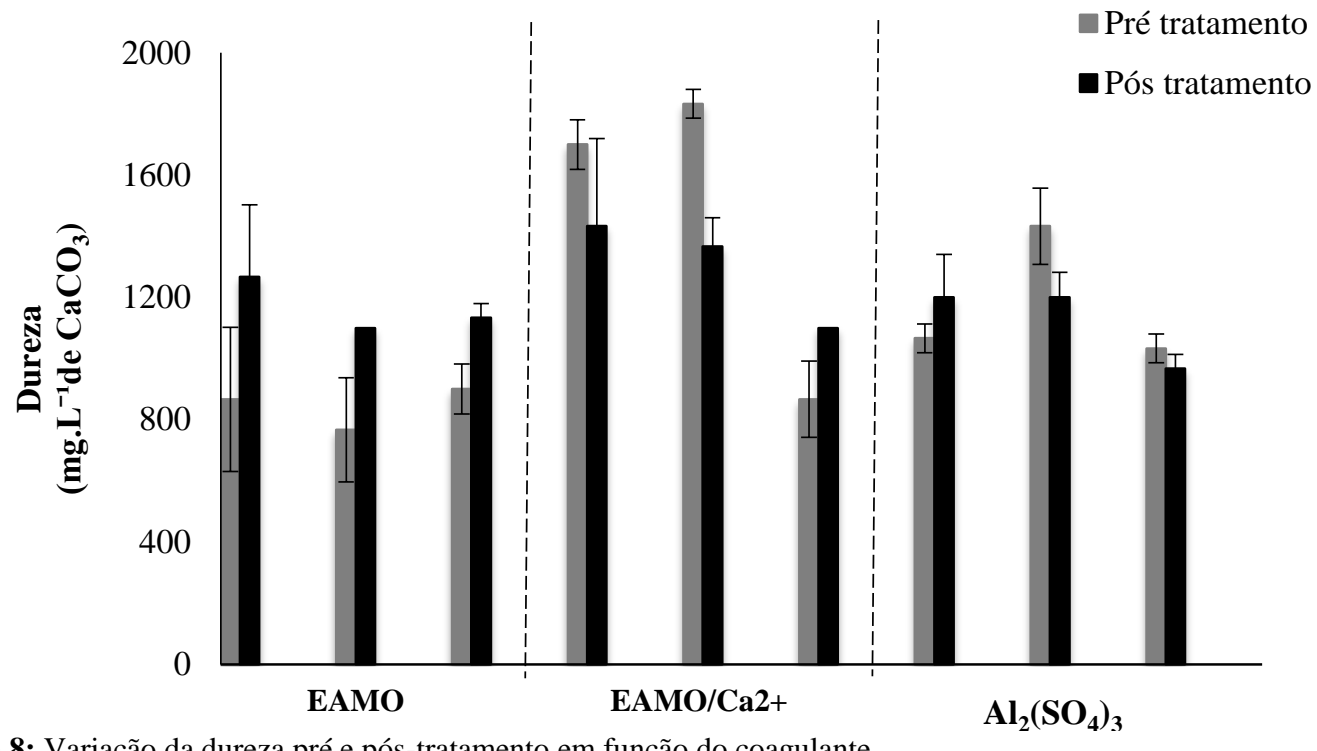

Figura 8: Variação da dureza pré e pós-tratamento em função do coagulante

Por meio da Figura 9, constata-se a não inferência dos tratamentos proposto no pH da água, sendo assim, a basicidade do resíduo líquido atende à NBR 15900 [30], que estabelece critérios para água de amassamento do concreto, cujo $\mathrm{pH}$ deve ser superior a 5. Todavia, não está em conformidade com a NBR 15527 [29] e NBR 15575 [31], limite entre 6 a 8, e USEPA [32] que estabelece os limites entre 6 a 9.

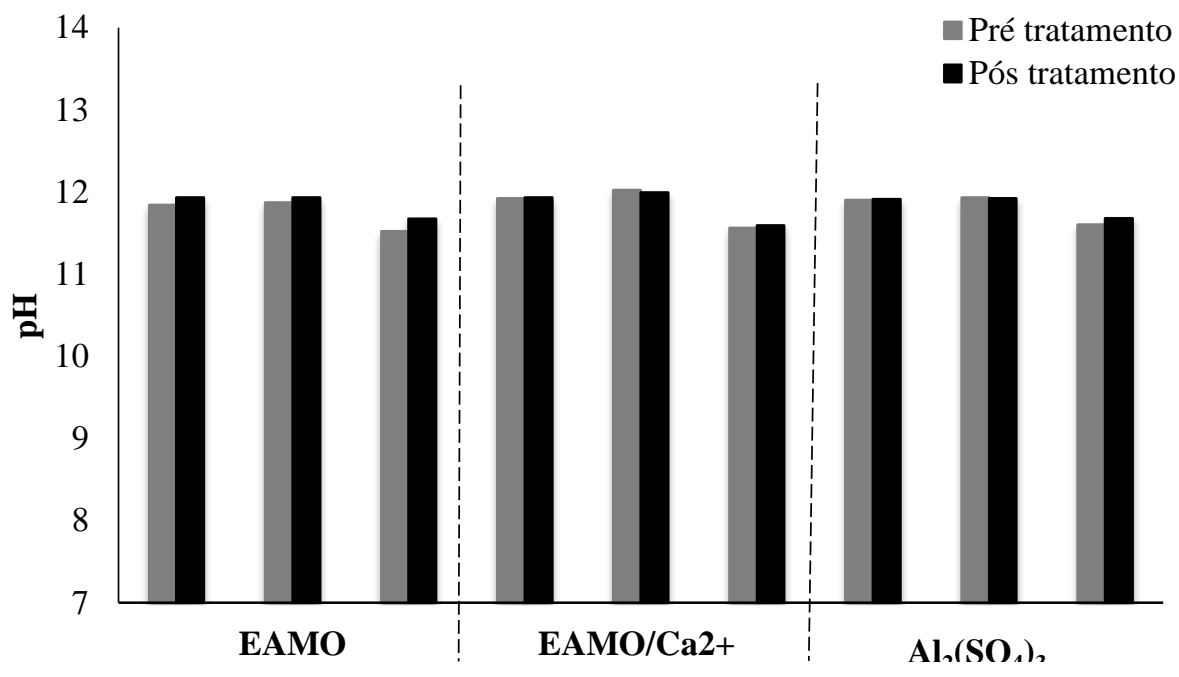

Figura 9: Variação do pH pré e pós-tratamento em função do coagulante

A remoção da turbidez com as dosagens ótimas foi superior a $85 \%$ para todos os coagulantes estudados, sendo que o EAMO/Ca2+ foi mais eficiente, promovendo remoção de $99 \%$ da turbidez do efluente, superior à média da remoção de turbidez obtida com o coagulante químico de $97 \%$ e com EAMO que foi de 90,6\% (Figura10). Assim sendo, o EAMO/Ca2+ foi considerado o mais eficiente no que se referente à remoção da turbidez. Considerando a média de todos os testes de turbidez os valores obtidos com a dosagem ótima desse coagulante e do extrato $\mathrm{Al}_{2}\left(\mathrm{SO}_{4}\right)_{3}$ enquadram-se nas NBR 15527 [29] e NBR 15575 [31] para uso menos restritivos, ou seja, turbidez menor ou igual a 5 UNT. 


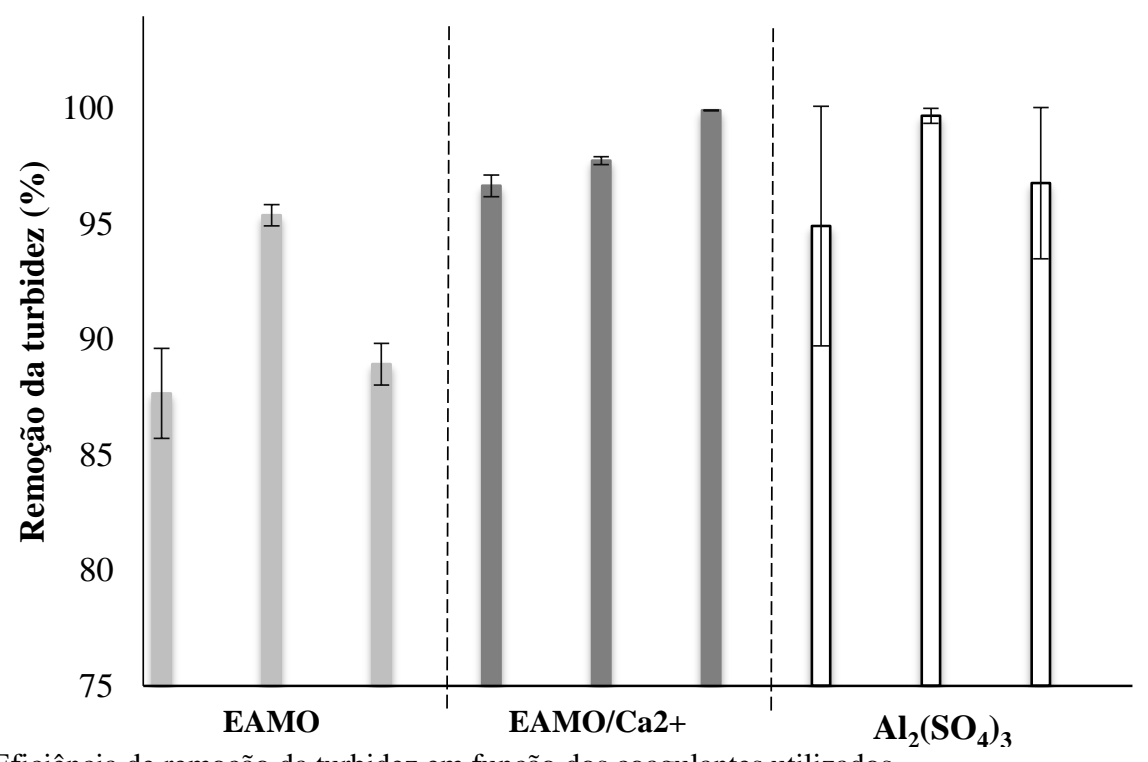

Figura 10: Eficiência de remoção da turbidez em função dos coagulantes utilizados.

A partir dos resultados apresentados, pode-se inferir que o EAMO/Ca2+ é mais eficiente no tratamento do resíduo líquido da central dosadora de concreto com elevada turbidez, além disso, trata-se de um coagulante natural, ou seja, um tratamento mais sustentável e menos agressivo ao meio ambiente.

Os tratamentos, considerado ótimo pelos resultados, foram realizados com valores de turbidez elevadas, acima de 100 UNT. Contudo, foram realizados alguns testes com água residuária de baixa turbidez inicial, inferior a $11 \mathrm{UNT}$, aplicando o extrato de o EAMO/Ca2+. Os resultados, apresentados na Figura 11, não apresentaram a mesma eficiência do que a observada na água com turbidez inicial acima de 100 UNT. Segundo Pritchard et al. [34] a presença de grande quantidade de partículas com carga negativas nas águas de turbidez elevada acabam exigindo mais do coagulante natural, carregado positivamente, para neutralizar as cargas e propiciar os processos de coagulação/floculação/sedimentação, dessa maneira, há uma maior remoção do material suspenso, tornando a Moringa oleifera mais eficiente em águas com elevada turbidez.

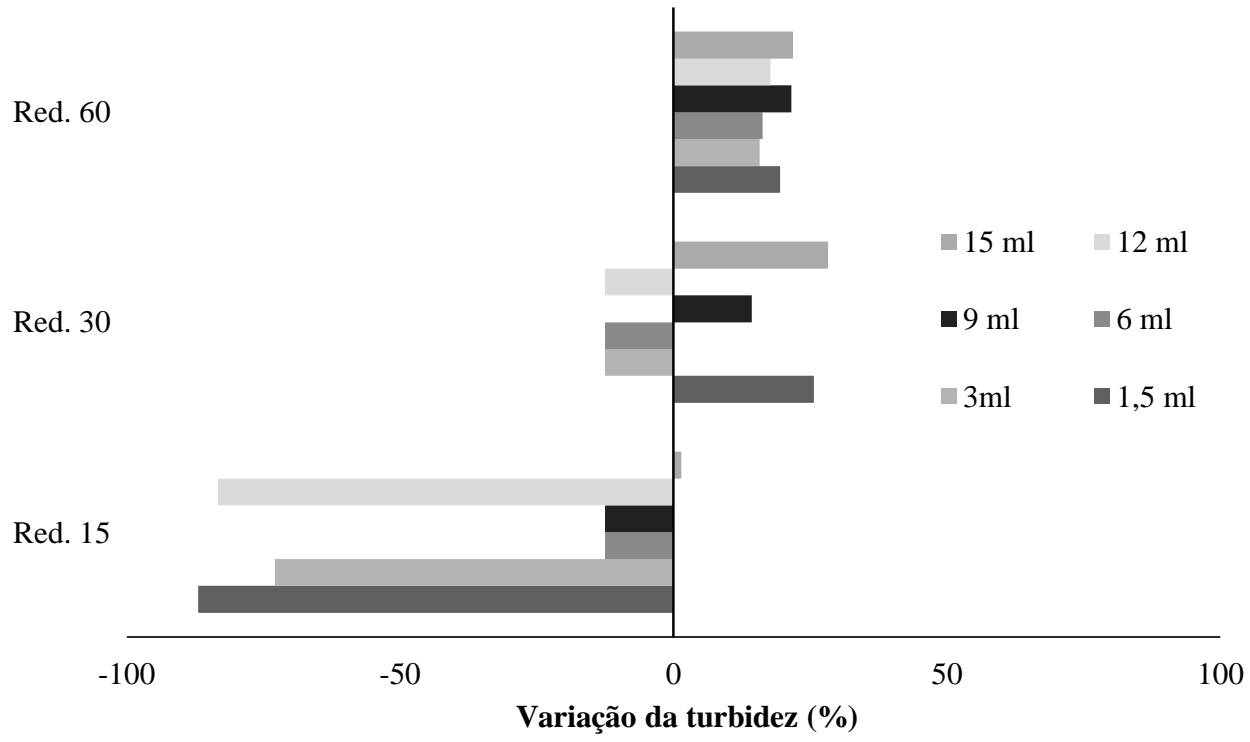

Figura 11: Ação do EAMO/Ca2+ em água com baixa turbidez. Percentuais positivos representam um aumento da turbidez quando comparados aos valores iniciais, já os percentuais negativos indicam remoção de turbidez.

Nesse viés, analisando a Figura 11, conclui-se que nos instantes inicias de sedimentação há remoção da turbidez, entretanto, o coagulante analisado não se mostrou eficaz com o aumento do tempo de sedimentação, ocasionando no tempo final de 60 minutos elevação da turbidez inicial. 
Portanto, após a avaliação dos coagulantes analisados, pode-se admitir que o de maior eficiência foi o EAMO/Ca2+, cujos resultados evidenciaram maior impacto no que se refere à diminuição dos parâmetros e adequação nas normas referência. Desta forma, ao empregar este coagulante, há conformidade do resíduo pós tratamento com a NBR 15527 [29] nos limites estabelecidos para cloro residual livre e turbidez para usos menos restritivos, NBR 15900 [30] para mínimo de pH, a NBR 15575 [31] para os valores estabelecidos para cloro residual livre e turbidez e, além disso, classificação da água como muito dura por Von Sperlin [33]. Por esse ângulo, os resultados obtidos para os parâmetros analisados possibilitam a empregabilidade da água residuária tratada para fins não potáveis como, por exemplo, rega de jardins e lavagem de veículos, além do uso como água para amassamento do concreto.

\section{CONCLUSÕES}

Mediante os ensaios efetuados, constatou-se a viabilidade do tratamento da água residuária da central dosadora de concreto com coagulantes natural e químico. Nesse seguimento, determinou-se a dosagem ótima como sendo aquela que com uma menor quantidade de coagulante possibilitasse remoção de $99 \%$ da turbidez; sendo assim, o melhor desempenho para os coagulantes testados foi verificado com o tempo de sedimentação de 60 minutos empregando para o EAMO com 7,0 mL.L $\mathrm{L}^{-1}$, EAMO/Ca2+ com 6,0 mL.L $\mathrm{L}^{-1}$ e extrato $\mathrm{Al}_{2}\left(\mathrm{SO}_{4}\right)_{3} \operatorname{com} 3,0 \mathrm{~mL} \cdot \mathrm{L}^{-1}$.

Ao avaliar os parâmetros antes e após o tratamento com concentrações ótimas obteve-se para alcalinidade redução de 311,11 mg.L $\mathrm{L}^{-1} \mathrm{CaCO}_{3}(22 \%)$ com EAMO/Ca2+ e $200 \mathrm{mg} . \mathrm{L}^{-1} \mathrm{CaCO}_{3}(16 \%)$ com o extrato $\mathrm{Al}_{2}\left(\mathrm{SO}_{4}\right)_{3}$. O pH manteve-se constante com valores entre 11,52 e 12,02, o cloro residual livre permaneceu constante mesmo com a aplicação dos coagulantes com valores entre 0,10 e $0,25 \mathrm{mg}$. $\mathrm{L}^{-1}$. O parâmetro dureza teve um aumento de $322,22 \mathrm{mg} \cdot \mathrm{L}^{-1} \mathrm{CaCO}_{3}(38 \%)$ com utilização do EAMO e redução de $166,67 \mathrm{mg} . \mathrm{L}^{-1} \mathrm{CaCO}_{3}(11,4 \%)$ com EAMO/Ca2+ e 55,56 mg. $\mathrm{L}^{-1} \mathrm{CaCO}_{3}(4,7 \%)$ com $\mathrm{Al}_{2}\left(\mathrm{SO}_{4}\right)_{3}$. A eficiência de remoção da turbidez foi superior a $85 \%$ para todos os coagulantes estudados na dosagem ótima, destacando maior eficiência para o EAMO/Ca2+ com redução de 99\% da turbidez do efluente.

Após a avaliação dos coagulantes estudados determinou-se como sendo o de maior eficiência o EAMO/Ca2+, cujos resultados de remoção das variáveis estudadas evidenciaram maior impacto no que tange a redução dos parâmetros e conformidade com as normas referência. Logo, o resíduo pós tratamento atende a NBR 15527 [29] nos limites estabelecidos para cloro residual livre e turbidez para usos menos restritivos, NBR 15900 [30] para mínimo de pH, a NBR 15575 [31] para os valores estabelecidos para cloro residual livre e turbidez e classificação da água como muito dura. Sendo assim, o tratamento possibilita empregabilidade da água residuária para fins não potáveis e amassamento do concreto. Ademais, destaca-se o viés sustentável do coagulante, haja vista tratar-se de um extrato natural.

\section{AGRADECIMENTOS}

Agradecemos a empresa Brasmix Engenheiros Associados Ltda pelo apoio nos ensaios e a Universidade Federal de Goiás pelo uso dos equipamentos e aporte financeiro de bolsa.

\section{BIBLIOGRAFIA}

[1] SILVA, D. F., LIMA, G. F. C. "Empresas e meio ambiente: Contribuições da legislação ambiental." Interthesis, v.10, n. 2, pp. 334-359, 2013.

[2] VIEIRA, L. B. P. "Implantação de modelo sustentável para centrais dosadoras de concreto: Redução do volume de resíduos com o uso de estabilizador de pega em centrais dosadoras de concreto", In: 52 Congresso Brasileiro do Concreto, 15 pp, Fortaleza, 2010.

[3] SNIC - Sindicato Nacional da Indústria do Cimento. Relatório Anual 2012-2013. Rio de Janeiro: [s.n.], 40 pp, 2013. Disponível em: http://snic.org.br/assets/pdf/relatorio_anual/rel_anual_2013.pdf. Acessado em maio de 2017.

[4] ZERVAKI, M., LEPTOKARIDIS, C., TSIMAS S. "Reuse of By-Products from Ready-Mixed Concrete Plants for the Production of Cement Mortars", Journal of Sustainable Development of Energy, Water and Environment Systems, v. 1, n. 2, pp. 152-162, 2013.

[5] SEALEY, B.J., PHILLIPS, P.S., HILL, G.J. "Waste management issues for the UK ready mixed concrete industry”, Resources, Conservation and Recycling, v. 32, n. 3-4, p. 321-331, 2001. 
[6] LOBO, C.; MULlingS, G. M. "Recycled water in ready mixed concrete operations", Concrete InFOCUS, v. 2, pp. 1-10, 2003.

[7] SANDROLINI, F., FRANZONI, E. "Waste wash water recycling in ready-mixed concrete plants", Cement and Concrete Research, v. 31, n. 3, pp. 485-489, 2001.

[8] SU, N., MIAO, B., LIU, F. "Effect of wash water and underground water on properties of concrete", Cement and Concrete Research, v. 32, n. 5, pp.777-782, 2002.

[9] CHATVEERA, B; LERTWATTANARUK, P e MAKUL, N. "Effect or Sludge Water from Ready-mixed Concrete Plant on Properties and Durability of Concrete Cement and Concrete Composites", Cement and Concrete Composites, v. 28, n. 5, pp. 441-450, 2006.

[10] EKOLU, S. O.; DAWNEERANGEN, A. "Evaluation of recycled water recovered from a ready-mix concrete plant for reuse in concrete", Journal of the South African Institution of Civil Engineers, v. 52, n. 2, pp. 77-82, 2010.

[11] TSIMAS, S; ZERVAKI, M. "Reuse of waste water from ready-mixed concrete plants", Management of Environmental Quality: An International Journal, v. 22, n. 1, pp. 7- 17, 2011.

[12] PAULA, H.M.; ILHA, M. S. O. "Quality of concrete plant wastewater for reuse", Ibracon Structures and Materials Journal, v. 7, pp. 349-366, 2014.

[13] PAULA, H.M.; FERNANDES, C.E. "Gestão da água em usina de concreto: analise do risco das atividades e monitoramento da qualidade da água residuária para fins de reuso", REEC-Revista Eletrônica de Engenharia Civil. v.10, n. 1, pp.14-21, 2015.

[14] COSGUN, N.; ESIN, T. "A study regarding the environmental management system of ready mixed concrete production in Turkey", Building and Environment, v. 41, n. 8, pp. 1099-1105, 2006.

[15] De PAULA, H.M., ILHA, M.S.O., ANDRADE, L.S. "Concrete plant wastewater treatment process by coagulation combining aluminum sulfate and Moringa oleifera powder", Journal of Cleaner Production, v. 76, n. 1, pp. 125-130, 2014.

[16] NDABIGENGESERE, A., NARASIAH, K. S., TALBOT, B. G., "Active agents and mechanism of coagulation of turbid waters using Moringa oleifera", Water Research, v.29, n.2, pp.703-710, 1995.

[17] CARDOSO, K. C., BERGAMASCO, R., COSSICH, E. S., et al., "Otimizing mixture and decantation times in the process of coagulation/flocculation of raw water using Moringa oleifera Lam", Acta Scientiarum Technology (UEM), v.30, n. 2, pp.193, 2008.

[18] MADRONA, G., SERPELLONI, G., SALCEDO, A. V., et al., "Study of the Effect of Saline Solution on the Extraction of the Moringa oleifera Seed's Active Component for Water Treatment", Water, Air, \& Soil Pollution, v.211, n.1, pp.409-415, 2010.

[19] MADRONA, G. S., BRANCO, I. G., SEOLIN, V. J., et al., "Evaluation of extracts of Moringa oleifera Lam seeds obtained with $\mathrm{NaCl}$ and their effects on water treatment", Acta Scientiarum. Technology (UEM), v.34, n.3, pp.289, 2012.

[20] ABATNEH, Y., SAHU, O., YIMER, S., "Purification of drinking water by low cost method in Ethiopia.', Applied Water Science, v.4, n.4, pp.357-362, 2014.

[21] MOLINA, N. F., RODRÍGUES, E. J. M., ARIZA, P. V., "Coagulantes naturales en sistemas de flujo continuo, como sustituto del Al2(SO4)3 para clarificación de aguas", Producción + Limpia, v.11, n.2, pp.4154, 2016.

[22] OKUDA, T.; BAES, A. U.; NISHIJIMA, W.; OKADA, M., "Improvement of extraction method of coagulation active components from Moringa oleifera seed", Water Research, v.33, n.15, pp.3373-3378, 1999.

[23] YIN, C. Y., "Emerging usage of plant-based coagulants for water and wastewater treatment", Process Biochemistry, v.45, n.9, pp.1437-1444, 2010.

[24] ARGUELlO, J. R., FERIA, J. D., PATERNINA, R. U., et al., "Sinú River raw water treatment by natural coagulants/Tratamiento de agua cruda del Río Sinú con extractos coagulantes naturales." Revista Facultad de Ingeniería Universidad de Antioquia, n.76, pp.90-98, 2015.

[25] GÁMEZ, L. S., LUNA-DELRISCO, M., CANO, R. "Comparative study between M. oleifera and aluminum sulfate for water treatment: case study Colombia”, Environmental Monitoring and Assessment, v.187, n.10, pp.1-9, 2015. 
[26] LO MONACO, P.A.V., MATOS, A.T., PEREIRA, M.S., et al., "Efeito da adição de diferentes substâncias químicas no extrato de sementes de moringa utilizado como coagulante no tratamento de esgoto sanitário", Engenharia Agrícola, v. 34, n. 5, pp. 1038-1048, 2013.

[27] PAULA, H. M. Uso de suspensões preparadas com sementes de moringa oleifera associada a coagulantes químicos no tratamento da água residuária de usinas de concreto. Tese de D.Sc., Universidade Estadual de Campinas. São Paulo, 2014.

[28] MUNIZ, G. L., DUARTE, F.V., OLIVEIRA, S. B. "Uso de sementes de Moringa Oleifera na remoção da turbidez de água para abastecimento", Revista Ambiente \& Água, v. 10, n. 2, pp.454-463, 2015.

[29] ASSOCIAÇÃO BRASILEIRA DE NORMAS TÉCNICAS, Água de chuva - Aproveitamento de coberturas em áreas urbanas para fins não potáveis - Requisitos, NBR 15527, Rio de janeiro, 2007.

[30] ASSOCIAÇÃO BRASILEIRA DE NORMAS TÉCNICAS, Água para amassamento do concreto Parte 1: Requisitos, NBR 15900, Rio de Janeiro, 2009.

[31] ASSOCIAÇÃO BRASILEIRA DE NORMAS TÉCNICAS, Edificações Habitacionais — Desempenho Parte 1: Requisitos gerais, NBR 15575-1:2013, Rio de Janeiro, 2013.

[32] U.S. ENVIRONMENTAL PROTECTION AGENCY (USEPA). Guidelines for Water Reuse. EPA. EPA/600/R-12/618, September 2012. Environmental Protection Agency. Washington, D.C.

[33] VON SPERLING, M. Introdução à qualidade das águas e ao tratamento de esgoto. 3nd ed. - Belo Horizonte: Departamento de Engenharia Sanitária e Ambiental, Universidade Federal de Minas Gerais; 2005.

[34] PRITCHARD, M., CRAVEN. T., MKANDAWIRE, T., et al., "A study of the parameters affecting the effectiveness of Moringa oleifera in drinking water purification", Physics and Chemistry of the Earth, v.35, n.13, pp.791-797, 2010.

\section{ORCID}

Thaynara de Almeida Corrêa e Silva Heber Martins de Paula https://orcid.org/0000-0001-6660-8412

https://orcid.org/0000-0002-7066-1408 